\title{
Landscape challenges to ecosystem thinking: Creative flood and drought in the American Southwest*
}

\author{
STUART G. FISHER, JILL WELTER, JOHN SCHADE and JULIA HENRY \\ Department of Biology, Arizona State University, Tempe, AZ 85287, USA.
}

\begin{abstract}
SUMMARY: Stream ecology is undergoing a transition from ecosystem to landscape science. This change is reflected in many studies; work at Sycamore Creek in Arizona will be used to illustrate the challenges of this transition and several applications. Conceptual challenges involve clear determination of the organization of research objectives. Ecosystem science is largely concerned with how things work while landscape ecology focuses on the influence of spatial pattern and heterogeneity on system functioning. Questions of system scale, hierarchical structure, dimensionality, and currency must be resolved in order to productively execute research objectives. The new stream ecology is more integrative, more realistic spatially, deals with streams at a larger scale, and treats them as branched system more than former approaches. At Sycamore Creek, studies of sand bar patches and their influence on organisms and nutrient cycling illustrate how variations in patch shape and configuration can alter system outputs. Beyond sandbars, inclusion of riparian zones as integral parts of streams produces a more coherent view of nutrient dynamics than previous studies that began at the water's edge. Integration of streams with the landscape they drain requires that streams be viewed as branched structures, not linear systems. This view in ecology is in its infancy but it provides an opportunity to identify processing hot spots along flow paths and to reveal presumptive effects of climate change in terms of spatial shifts in biogeochemical activity rather than black-box rate changes.
\end{abstract}

Key words: ecosystem, landscape, stream, flood, drought, riparian, nitrogen, biogeochemistry.

\section{INTRODUCTION}

Stream ecology has been largely an ecosystem science for the past quarter century. Recently, stream ecologists have applied some of the ideas of landscape ecology to stream science. Unfortunately, few landscape ecologists have used streams as research laboratories for testing concepts of general application. Exceptions have viewed streams as arenas for study and have resolved spatial heterogeneity within the bounds of the linear channel (Sinsabaugh et al., 1991; Dent et al., 2001). This conceptual evolution of stream ecology as a sub-discipline has been mirrored in the structure of research in the Sycamore

\footnotetext{
*Received July 9, 2001. Accepted August 2, 2001.
}

Creek Project in Arizona, USA. Our objectives in this paper are to use the Sycamore Creek project as a case study to illustrate how this conceptual transition has taken place and to discuss several issues that underlie this change from ecosystem ecology to landscape science.

The Sycamore Creek study began as a study of succession in running waters. Flash flooding was the disturbance and changes in population, community and ecosystem attributes were monitored over time (Fisher et al., 1982). The sampling scale was essentially the square meter and spatial heterogeneity was scarcely considered. Data were scaled up to the reach (ca. $100 \mathrm{~m}$ ) but spatial variation was ignored. The ecosystem in these early studies was considered the wetted channel and when the channel dried the 
ecosystem disappeared. Later studies elaborated recovery mechanisms in terms of life history strategies of invertebrates, primary production, and nutrient cycling (Fisher and Gray, 1983; Busch and Fisher, 1981; Grimm and Fisher, 1986). As research progressed, we met several challenges of interpreting observed patterns by invoking processes within the spatial and temporal confines of the wetted channel. Thus we expanded the system boundaries to include first the hyporheic zone (Valett et al., 1990), then sand bars (Holmes et al., 1994), then the riparian zone (Schade and Fisher, 1997; Marti et al., 2000). Since flash floods originated as precipitation falling at distant sites, we began to consider processes that occurred outside the main stem (e.g. in tributaries) and in upland terrestrial systems. While this required an expanded spatial perspective it also forced us to incorporate spatial (and temporal) heterogeneity. Not surprisingly, the stream was dry at times and places and certain processes occurred there and then as well. Drying was studied first as an alternative disturbance (to flooding) but it forced us to think at large scales and to incorporate the "terrestrial" ecosystem component into our understanding of stream structure and functioning (Stanley et al., 1997; Grimm and Fisher, 1992). This is where we are today and it is this perspective that we will illustrate in this paper. We will present three short case studies illustrating how ecological understanding is enhanced by resolving issues in a spatially explicit manner and will try to highlight research challenges that loom on the horizon.

This gradual transition from ecosystem to landscape approaches has required several important changes in the way we think about streams. We think these are general and would apply in an expanded approach to any ecological system.

\section{Pattern-process linkage}

Patterns are the observations we attempt to explain by invoking alternative, multiple processes (hypotheses). As such, the pattern-process connection is central to hypothetico-deductive science (Fisher, 1994). This approach is nothing new but its connection with landscape ecology presents a novel wrinkle. Landscape ecologists may certainly observe patterns in landscapes (spatial patterns) or in landscapes over time (temporal patterns) and search for causes of these patterns. For example, what causes changes in terrestrial vegetation from mountain tops to foothills? Landscape ecology takes this a step further and asks, what are the consequences of spatial pattern for some usually large scale process? For example, do strips of terrestrial vegetation influence the movement of materials downslope? Is this effect altered if the size or sequence (i.e. configuration) of these banded slopes is changed? In this sense, landscape ecology is asking how pattern (in space) alters process; that is, spatial pattern is an independent variable (Turner, 1989; Meentemeyer and Box, 1987).

\section{Context}

In stream ecology, two approaches can be adopted. We may do landscape ecology in streams or we may do landscape ecology of streams (Fisher, 1994). In the former case we would view streams, however defined, as the systems of interest and ask how spatial pattern influences process therein. For example, how do runs and riffles and pools interact? Does their sequence matter? Alternatively, streams can be viewed as a patch in a larger terrestrial landscape. In this case, streams represent transport corridors or boundaries or simply habitat patches for certain organisms such as fish and mosquitoes.

\section{Size, scale and hierarchy}

While there is some disagreement over whether landscape ecology is restricted to certain large scales or applies to the study of spatial heterogeneity wherever it occurs, in practical terms, the scale of an ecological investigation must be determined (Wiens, 1989; Pickett et al., 1989). Often, stream studies are of reaches which are defined in terms of what is seen by a human observer standing on the bank. But excellent smaller (insect habitat selection, leaf decomposition) or larger (river continuum, river basin) studies also exist. Size and scale are related except that scale connotes a relationship with hierarchical structure. A thorough discussion of hierarchy theory as it relates to streams is beyond the scope of this paper. Suffice it to say that there are several ways to increase system size and the most useful is to do it in the context of a hierarchy. For example, a study of fish in a $2 \mathrm{~km}$ reach of small stream could be increased in scale by examining a $2 \mathrm{~km}$ reach of continental river. Alternatively, scale could be increased by adding ecosystem components, such as the hyporheic or riparian zones or by examining longer and longer linear reaches or by expanding the study to include dendritic drainage networks. Each 
of these scaling decisions is grounded in a different concept of the river system. A hierarchical approach forces us to deal with that central question. Furthermore, a hierarchical approach allows us to examine the structure of the system in an objective manner to determine natural scales for analysis, for example, by examining discontinuities (breaks) in fractal dimensions.

\section{Dimensionality}

Stream studies must be grounded in a spatial dimension. Streams are traditionally embraced in one or two-dimensional terms. Streams are considered linear systems (1-D) and several of the most significant advances in understanding of streams are limited to this view (river continuum concept, material spiraling). Other studies, especially those involved in biological sampling are 2-dimensional in that streams are dominated by benthic organisms. Plankton is rare or non existent. Larger rivers with significant plankton and hyporheic studies require a three-dimensional view. Time adds an additional dimension to each of these.

Hierarchy theory teaches us that fractal dimensions may be significant as well. The fractal dimension tells us how an entity fills space. A one-dimensional stream is a line and a two-dimensional one is a plane (e.g. a catchment). The branched stream network is a fractional dimension, in this case the fractal is between 1 and 2 and tells us how the branched network fills the plane. Fractal dimensions between 2 and 3 may also be instructive but have not been used to describe streams. Such an analysis would incorporate changes in elevation. Consideration of fractals leads to the concept of self-similarity. Small drainage trees are similar in shape to large drainage trees; meanders in small streams have the same shape parameters as meanders in large rivers (within a limited range of scales). This suggests interesting questions about how ecological function changes as a function of scale (effect of pattern on process) if shape is conserved, or how shape influences function if scale (size) is conserved.

\section{Currency and Approach}

This idea of "function" is related to the idea of currency or "observation set” (O’Neill et al. 1986). Why are we studying the stream? What of the many things it does are we interested in? For example, the stream may provide a habitat for fish and at the same time it transports water and materials. It may influence riparian vegetation in certain ways and transforms nitrogen in various ways. Each of these perspectives (currencies) may yield a differently structured system in terms of hierarchical units and fractal dimension. Depending on the currency, the appropriate scale for study may change. Or certain currencies may converge on a common structure. Stream ecology has not yet dealt with these questions of general ecological significance. Surely any given study of a stream or set of streams must be focused on a subset of possible observations. In Sycamore Creek for example, we have focused recently on the stream as a biogeochemical processor of nitrogen. This is the observation set that we will emphasize in the case studies presented below. With this approach, we need to identify operative patches in the system of interest, determine how they are connected, and resolve the changes (in through-flowing nitrogen) which occur in each. Once that is determined, effect of altered patch structure, processing, and connections can be evaluated. As you will see in the sections which follow a variety of scales are involved in these studies of Sycamore Creek.

\section{SAND BARS AS FUNCTIONAL LANDSCAPE PATCHES}

The concept of streams as a surface water system is limited. Water moving in channels exchanges vertically and horizontally with adjacent subsystems such as hyporheic sediments, sand bars, and riparian zones. Sand bars are especially interesting in that they can occur in a variety of sizes and shapes. Furthermore, these shape parameters change over time after disturbance events such as flash flooding. Water moves freely (but slowly) through sand bars, where it experiences a suite of chemical and physical changes. Sand can be incorporated in stream models as an interacting compartment without specifying spatial relationships, but a much more thorough understanding of how sand bars influence the stream as a whole can be understood if sand is modeled in a spatially explicit way. In the discussion below, we will describe not the model itself, but the biologic and chemical interactions upon which such a model might be based.

In the surface stream, water flows rapidly and organisms are exposed to light. In contrast, water flows more slowly through the alluvial interstices of 
sandbars and it does so in complete darkness. These physical differences result in striking biogeochemical differences. For instance, while rates of primary production can be very high in the surface stream of Sycamore Creek (Busch and Fisher, 1981), no photautotrophic production occurs in sandbar sediments. Microbial processes are often elevated in sandbar sediments because water flows more slowly and much sediment surface area is available for microbial attachment.

In several stream and river ecosystems including Sycamore Creek, (Triska et al., 1989; Claret et al., 1997; Coleman and Dahm, 1990; Holmes et al., 1994) elevated rates of transformations among forms of nitrogen have been demonstrated in sand and gravel bars. In the surface stream of Sycamore Creek, periphyton removes inorganic nitrogen from solution and convert it to biomass. Ultimately, nitrogen leaves algae as organic nitrogen by excretion or decomposition and enters the surface stream, thereby elevating organic nitrogen concentration. When surface water enters sandbars this organic nitrogen is converted to inorganic nitrogen through heterotrophic breakdown and subsequent nitrification by microbes in oxic sandbar sediments (Holmes et al., 1994). As a result of these processes dissolved nitrate increases as water moves through sandbars and is highest where it exits sandbars and re-enters the surface stream. While nitrate is generally higher at locations farther along flowpaths, not all sandbar flowpaths exhibit net increases in nitrate. For instance, if along sandbar flowpaths, oxygen becomes depleted and sufficient organic matter is present, denitrification may be substantial in sandbar sediments making some sandbar sediments a permanent sink, removing $\mathrm{N}$ from the system (Holmes et al., 1995).

Spatial differences in nitrogen has important consequences for periphyton community composition, primary production, and stream nitrogen retention, especially in N-limited streams, such as Sycamore Creek (Grimm and Fisher, 1986). Nitrate is highest where water upwells from the hyporheic zone or outwells from sandbars. Chlorophyll-a and primary production are higher at hyporheic upwelling zones than at downwelling zones (Valett et al., 1994). Similarly, blooms of algae occur in locations where water outwells from sandbars, usually at their downstream edges (Holmes et al., 1994). Not only are algae more abundant at outwelling edges than at inwelling edges, but cyanobacteria (free living or symbiotic with certain diatom species) show the reverse pattern, being more abundant at inwelling edges where $\mathrm{N}$ is low.

We hypothesized that these community differences exist because sources of nitrate are available at outwelling edges of sandbars and algae, which are limited by inorganic nitrogen, can grow more easily at these edges because of this nitrate source. Because nitrogen fixation is metabolically costly, cyanobacteria are poor competitors under high inorganic nitrogen conditions (Gutshik, 1981) and grow well at inwelling edges where nitrogen is low. We have found strong correlations between nitrate concentrations at sandbar edges and algal biovolume (positive) and cyanobacterial biovolume (negative) at sandbar edges. Because of the spatial variation in $\mathrm{N}$ availability, "algal" communities are segregated with fixers abundant at inwelling zones at the heads of bars and non-fixers predominating at outwelling edges at the tail of bars. Because cyanobacteria fix dinitrogen, they represent a direct input of $\mathrm{N}$ to the ecosystem which is highest at inwelling edges. In contrast, non-fixers remove fixed $\mathrm{N}\left(\mathrm{NO}_{3}\right.$ and $\left.\mathrm{NH}_{4}\right)$ from solution at outwelling edges. We found that from $60-98 \%$ of outwelling nitrate is retained by algal mats at outwelling edges through a combination of both nitrate uptake by algae and denitrification in algal mats at sandbar edges. By their mere presence sandbars influence rates of nitrogen inputs, transformation among forms of nitrogen and retention of nitrogen as well as the community composition of periphyton in the surface stream and its spatial variability. However, sandbars themselves vary in size and shape and their variation may influence stream ecosystem processes.

The active channel of desert streams is dynamic. During flood events sandbars are rearranged and reshaped. They may also vary in composition in terms of organic inclusions, particle sizes, and packing. The configuration of multiple sandbars in a reach is also variable. Shortly after floods, many small bars of various shapes exist in the channel. Later, these coalesce into fewer larger bars. These structural variations may have several ecological consequences.

Rates of organic matter breakdown and nitrification in sandbars and retention by algae at outwelling edges are influenced by rates of flow through the sandbar which are dependent on hydraulic gradient through the sandbar and hydraulic conductivity. Nitrate retained by algal mats at outwelling edges is dependent on flow rates through the sandbar. Deposits of organic material (detritus, roots, root 
exudates) can elevate heterotrophic respiration leading to reduced oxygen and elevated denitrification (Schade et al., 2001). Distributions of sand bar vegetation, variations in hydraulic conductivity due to variations in sediment particle sizes, and variations in hydraulic gradient are features that vary substantially from sand bar to sand bar in a desert stream such as Sycamore Creek.

The length of a sand bar is also important for stream nitrogen cycling. From research done by Holmes et al. (1994) we know that nitrate concentrations increase along sand bar flowpaths. Therefore, up to a certain distance, a longer sand bar will have higher outwelling nitrate concentrations than a shorter sand bar. Because the nitrate curve plateaus, presumably occurring when the substrate is exhausted, after a certain distance longer bars do not have increasingly higher nitrate concentrations.

Because nitrate increases asymptotically with sand bar length, the way in which sand is distributed in multiple sand bars may also be important for stream nitrogen cycling. If a given volume of sand is distributed in a few long sand bars, less organic nitrogen will be transformed to nitrate than if that same amount of sand is distributed in many shorter bars (Fig. 1). In addition, a reach with few long bars may support less algal growth along its sand bar edges (because there are fewer edges) and it may export larger amounts of organic nitrogen to downstream ecosystems than would a stream reach with many small bars.

This study has shown that streams extend beyond the wetted perimeter and certainly include sand bars. An understanding of the influence of sand bars cannot be gained without a spatially explicit knowledge of the patch structure of the system and the relevant biogeochemical functioning of each patch (bar in this case). Since these relationships change dramatically in disturbance time (after flash flooding), patchiness must be resolved in a four-dimensional context. Clearly the black box, well-mixed reactor concepts of ecosystem ecology are inadequate to the task of understanding the structure and functioning of stream channels. This is even more true when the stream is expanded to include the riparian zone with its terrestrial plants.

\section{RIPARIAN VEGETATION AND ECOSYSTEM PROCESSES}

While higher plants are often included in stream studies, these are usually vascular hydrophytes. i.e. aquatic plants. Recently, studies of riparian trees and their interaction with streams as nutrient filters have been productive. These studies are often based on a three compartment model: upland, riparian strip, and surface water. Vegetation serves to alter water quality by "filtering" materials from water as it moves from upland to stream across the riparian zone. In nature, spatial patterns are more complicated than this and filtration or retention can take several forms. Arid land studies have illuminated the nature of terrestrial - aquatic exchanges by presenting us with more complicated patterns of water movement and we have come to understand that several different types of organisms are involved. Finally, flood prone desert systems have provided an opportunity to place spatially explicit riparian studies in a temporal context that is equally heterogeneous.

\section{A. Many small bars}

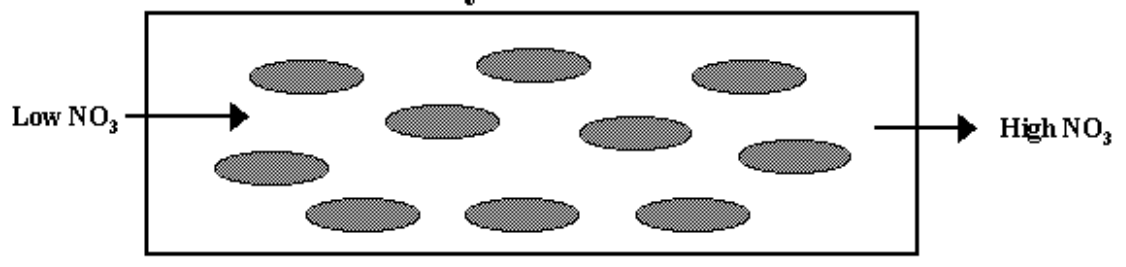

B. One large bar

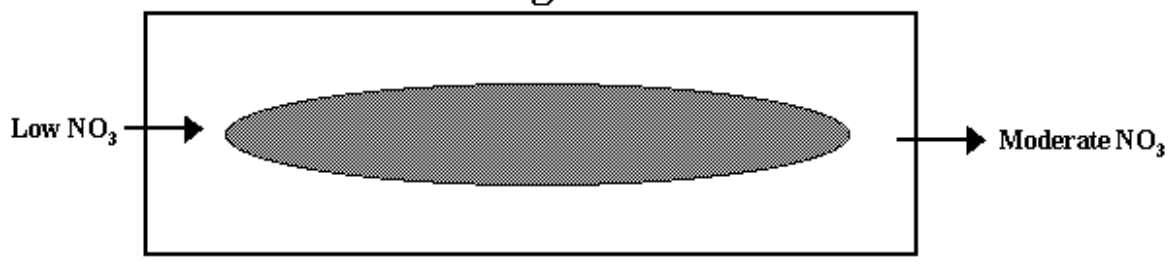

FIG. 1. - Hypothetical stream reaches with different sand bar configurations but identical sand bar surface area. A. Reach with many small sand bars. B. Reach with one large sand bar. Small sand bars produce more nitrate because nitrate increases asymptotically with sand bar length 
Studies of stream ecosystems have increasingly come to include riparian vegetation as part of the system of interest. The presence of riparian plants has been shown to influence nutrient cycling in streams through the retention of nutrients from subsurface water entering riparian soils from either upland or stream (Peterjohn and Correll, 1984; Lowrance et al., 1984; Groffman et al., 1992; Pinay et al., 1993; Lowrance, 1998; Hill, 2000). Much of the work establishing these relationships has taken place in mesic watersheds and tends to focus on the reach scale ( $\mathrm{km}$ scale). This focus on the reach scale, although very productive in providing information regarding the general function of riparian zones in the landscape, has limited our ability to either effectively analyze watershed-level influences of riparian zones on retention or clearly determine the precise mechanism by which riparian plants cause retention. Very little work on riparian - stream interactions has explicitly taken a multi-scale approach, or considered the importance of spatial heterogeneity of riparian vegetation in understanding riparian-stream interactions.

When rain falls on the Sycamore Creek watershed, it flows overland into small rivulets and channels that transport runoff water to larger perennial streams. In these larger channels water infiltrates coarse channel sediments and exchanges back and forth between stream and riparian zone as it moves down the catchment (Fetter, 1994). In the Sycamore Creek watershed, we have conducted research to help us better understand stream-riparian interactions including, 1) the magnitude and direction of hydrologic linkage between stream and riparian zone; 2) nitrogen retention by the riparian zone; and 3 ) the relative importance of potential retention mechanisms. However, due to the heterogeneous nature of this interaction, we utilized a multiple scale approach.

\section{Reach scale}

As mentioned above, much of what we know about stream-riparian interactions, particularly nutrient retention and hydrologic linkage, comes from the study of individual reaches. A number of approaches have contributed to our understanding of the mutual influence of stream and riparian zone at this scale. To explore hydrologic linkages, a common approach is to inject a conservative tracer, such as chloride or bromide and study patterns of dilution downstream from the injection site (Harvey and
Wagner, 2000). Non-conservative tracers, particularly nitrogen, have been used to gain insight into nutrient exchanges. For instance, nitrogen may be injected simultaneously with a conservative tracer to study declines in nitrogen concentration downstream of the addition point, providing an estimate of uptake length (Newbold et al., 1982) or nitrogen retention (Triska et al., 1989) in a spatial context. We conducted tracer additions, using both bromide (conservative) and ${ }^{15} \mathrm{NH}_{4}$ (non-conservative) in a $400 \mathrm{~m}$ reach of Sycamore Creek to trace the movement of both water and nitrogen through several components of the ecosystem (Schade et al., in prep.). We used these tracers to determine strength and direction of hydrologic linkage and nitrogen exchange between stream and riparian zone and to estimate $\mathrm{N}$ retention by riparian vegetation, both through uptake and denitrification. In our investigation, we found an increase in peak bromide concentration in riparian wells with distance downstream from the point of injection. This is contrary to results from many mesic studies where peak concentration decreases with distance from the injection point. We conclude from this pattern that water moves laterally out from stream to riparian zone along the length of this reach and little unlabeled groundwater moves into the riparian zone from either lateral movement from the uplands or up from deeper groundwater sources. Therefore, streamriparian hydrology differs greatly between xeric and mesic ecosystems.

We were also able to trace the movement of ${ }^{15} \mathrm{NH}_{4}$ from the surface stream into the riparian zone. We found that willow trees (Salix goodingii) were enriched in ${ }^{15} \mathrm{~N}$ following the addition, while other species of riparian trees were not (Fraxinus velutina, Platanus wrightii and Prosopis sp). These results indicate that willow trees take up stream water $\mathrm{N}$, while other trees do not. Since willow trees tend to grow closer to the stream channel than these other species, these results, along with mass balance calculations, suggest that $\mathrm{N}$ carried into the riparian zone through hydrologic exchange is quickly removed in a narrow strip at the interface between stream and riparian zone (Fig. 2). Different tree species do not have equal access to stream $\mathrm{N}$ as a resource simply because of their position in the landscape. Furthermore, nutrient retention does not occur uniformally throughout the riparian zone, but tends to occur more rapidly at areas of interface between riparian zone and either stream (Schade et al., 2001) or upland slope (McClain et al., 1994). 


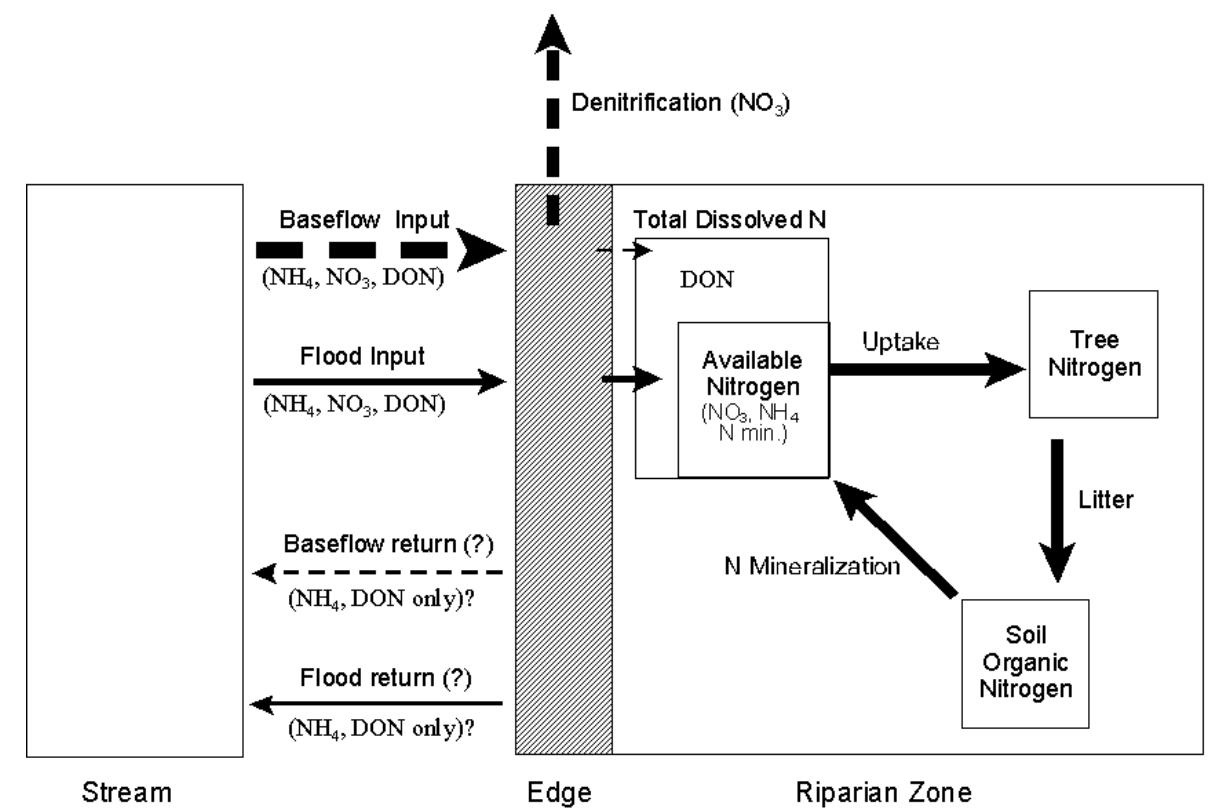

FIG. 2. - Diagram showing hydrologic and nutrient connections between surface flow ("stream”) and riparian zone.

This suggests that, at the reach scale, the riparian zone is not homogeneous and that the species composition and spatial arrangement of vegetation influences retention of stream water nitrogen. A broader look at Sycamore Creek shows that these variables are also heterogeneous at the section scale, and highlights the importance of a broader scale perspective when we consider the influence of the riparian zone on total watershed-level $\mathrm{N}$ retention.

\section{Catchment scale}

Estimating the importance of the riparian zone requires more than just scaling up the results from our reach scale study because riparian vegetation is heterogeneously distributed. A good estimate of the relative importance of retention by the riparian zone requires a larger scale analysis of the distribution and abundance of riparian vegetation. Density, species composition, and size distribution of riparian trees were measured along a $12-\mathrm{km}$ section of Sycamore Creek. This information was used to estimate production and $\mathrm{N}$ uptake by riparian trees, with an eye towards understanding spatial variation in retention through vegetative uptake. These reaches varied greatly in $\mathrm{N}$ uptake, which, not surprisingly, was heavily influenced by abundance and species composition of riparian trees, and was highly variable from reach to reach. In addition, the presence of vegetation has also been shown to have a positive influence on rates of denitrification (Schade et al.,
2001). If denitrification were included in this analysis, the influence of spatial variation in abundance of vegetation on retention would be much enhanced. We now not only have convincing evidence that riparian zones can be hot spots of $\mathrm{N}$ retention, but we have also seen that the importance of riparian zones can vary tremendously in space, necessitating explicit attention to large scale spatial heterogeneity.

\section{Stand scale}

As mentioned above, the presence of riparian vegetation has a positive influence on both $\mathrm{N}$ uptake and denitrification. The common link between these two potential $\mathrm{N}$ retention mechanisms and vegetation makes it difficult to determine the relative importance of them without manipulative experiments designed to test them separately. These manipulative experiments are obviously impossible to do at a $12-\mathrm{km}$ scale, and are very difficult at the reach scale as well. What is needed to do these experiments is a reduction in the scale of investigation to a system of manageable size.

The active channel of Sycamore Creek consists of both surface water and dry gravel bars. These gravel bars often support the growth of a woody shrub, Baccharis salicifolia, which is often distributed in patches of one or several individual plants bunched together. These patches are relatively isolated from each other by areas of open, uncolonized gravel bar. This distribution allows us to treat these 
patches as replicates in manipulative experiments. Since these patches are generally less than $1 \mathrm{~m}^{2}$ in area and the plants are relatively hardy, we were able to transplant individual plants, as well as perform other manipulative experiments, allowing us to differentiate the relative importance of uptake and denitrification. In general, we found high rates of $\mathrm{N}$ retention and denitrification in sediments from colonized patches. These effects were lost when the plant was removed and established in previously uncolonized locations when plants were transplanted. The results of these experiments provided strong evidence that most $\mathrm{N}$ retention observed in Baccharis colonized gravel bars was due to denitrification fueled by organic matter production by the plant (Schade et al., 2001).

These studies of the riparian zone show that hydrologic connections between riparian zone and surface stream are strong and significant in terms of processing and retention of materials. Several mechanisms are involved and these processes vary greatly in space and time. To understand how streams operate, we require a multi-scale, spatially explicit understanding of spatial patterns of riparian vegetation and hydrologic exchange with the stream, as well as temporal variation due to season or disturbance effects (succession).

\section{STREAM-UPLAND CONNECTIONS}

Whether spatially explicit or not, stream studies have usually embraced the stream as a linear ecosystem of indeterminate length. As stated before, tributaries are conceptual nuisances. Watershed (catchment) models usually include a terrestrial, an aquatic, and an atmospheric compartment (Likens et al., 1967). This conception, while useful in mass balance terms, tells us nothing about where and when important transformations occur. Nor does this model help us understand how streams inter-digitate with the land and render the entire complex an integrated throughflow system. In reality, streams begin as precipitation strikes the land surface, and at this point the ratio of terrestrial to aquatic influence is large indeed. Conceptually, stream ecosystems are far away, yet in reality, this is where they begin.

\section{Terrestrial-aquatic continuum}

Raindrops strike dry desert soil and move across the landscape through patches with variable topog- raphy and vegetative cover, en route to the downstream, more aquatic components of the watershed. Yet, how do we define "terrestrial" and "aquatic" components of watersheds? In reality, we see a continuum from "more terrestrial" to "more aquatic" as we follow the movement of water from the highest ridge tops in the catchment, into the smallest rivulets that drain upland slopes, and into progressively larger channels. To date, most terrestrial studies have ignored the role of streams in nitrogen transport and processing (Vitousek and Reiners, 1975; Peterjohn and Schlesinger, 1990), while most stream studies have neglected the drainage networks that reach up into the terrestrial environment, comprising the terrestrial-aquatic continuum. Likewise, stream ecologists have developed concepts including energy and nutrient budgets (Fisher and Likens, 1973; Meyer and Likens, 1979; Grimm, 1987) and nutrient spiraling (Newbold et al., 1981) in short reaches of large permanent streams; however, these streams occupy the most aquatic end of the continuum and do not adequately represent the complex networks of streams found in any watershed.

Stream ecologists have operationally defined first order streams as the smallest streams that maintain perennial flow (Allan, 1995). This typical usage of stream order makes ecosystem comparisons difficult, since a stream defined as first order in the Sonoran Desert may differ dramatically in width, depth, discharge and catchment area from a first order stream located in a temperate deciduous forest. Furthermore, variation in the accuracy of maps, map scale and difference between wet and dry years (Allan, 1995) makes the definition of stream order even more subjective. This operational definition adopted by stream ecologists is not in agreement with the more strict geomorphic definition of stream order originally proposed by Horton (1945) and Strahler (1964), where a first order stream is the smallest unbranched channel on the ground. In our research, we are working to resolve previous "black box" models both spatially and temporally, considering streams as branched networks that occupy the full extent of the terrestrial-aquatic continuum.

\section{Nitrogen retention}

Our interest in nitrogen processing and removal along the terrestrial-aquatic gradient is motivated by several observations. Inorganic nitrogen in Sycamore Creek flood water is high and variable in time. Peak concentrations occur in floods following 
long droughts, and concentrations decrease with increasing flood frequency (Grimm and Fisher, 1992). These observations suggest that nitrogen accumulates in the ecosystem between storms, while large infrequent rain storms result in release and transport of nitrogen to downstream ecosystems. In addition, mass-balance calculations show that nitrogen input generally exceeds export in arid lands of the Southwest (Schlesinger et al., 1999; Peterjohn and Schlesinger, 1990), including Sycamore Creek (Grimm, 1987). In the Sycamore Creek watershed, only ten percent of the nitrogen supplied in annual atmospheric deposition is exported in surface runoff from the catchment; yet, we do not know the fate of the missing nitrogen or the location of "hot spots" in the landscape that are responsible for nitrogen removal.

In addition, rain that falls on these desert landscapes is highly variable in both space and time. Summer monsoon storms are typically small in spatial extent and short in duration (Sellers and Hill, 1974), but these storms are intense and can produce a large amount of rain in a short period of time. In contrast, winter storms tend to be less intense but of longer duration, and across both summer and winter rain seasons, rainfall amount associated with individual storms is highly variable. This variation in rainfall may influence the location of nitrogen processing and retention in the watershed.

There are several mechanisms that may remove nitrogen from runoff water as it moves through the watershed. Nitrogen may be stored in plant biomass or soil, or it may be permanently lost to the atmosphere as a result of volatilization of ammonia or denitrification, which transforms nitrate to nitrogen gas (Sprent, 1987). In general, some retention mechanisms act on ammonium, some on nitrate, and each requires a specific set of conditions to operate; conditions that may vary considerably along the terrestrial-aquatic continuum.

Data collected in the Sycamore Creek Watershed indicate that during the earliest storms in a rain season, runoff is dominated by ammonium while later storms produce nitrate-dominated runoff. Since nitrification is more sensitive to water stress than mineralization (Sprent, 1987), nitrification may be quite low prior to the onset of the rain season, causing this seasonal pattern. Soil moisture not only varies seasonally, but also in relation to topographic position, which may influence nitrogen transformations across the landscape. For example, Ohte et al. (1997) found that lysimeter samples from dry slopes contained both ammonium and nitrate, while samples from wet slopes contained only nitrate, and saturated samples contained neither ammonium nor nitrate. This study suggests that nitrification was inhibited in the driest sites, while dentrification predominated in the saturated sites. Therefore, we would expect nitrogen retention via ammonium adsorption or volatilization to be highest under dry conditions, while denitrification would predominate under saturated conditions. Yet, the mode of retention varies spatially and temporally.

The process of denitrification requires organic carbon and localized zones of anoxia (Sprent, 1987); therefore, patches in the landscape with high moisture and organic matter may stimulate denitrification. Given these requirements, we might expect "hot spot" intensity for denitrification to increase with stream order or size, with the highest rates of denitrification occurring along streams with well developed riparian zones where organic matter content and moisture are both high. However, on an areal basis, most of the catchment is composed of dry upland patches, dotted with a mix of desert shrubs and trees. During storms, conditions are also favorable for denitrification under the canopies of these "more terrestrial" desert shrubs. Therefore, storms may in essence, switch on nitrogen transformations in the drier components of the watershed, but they may remain active (on) for only a short period of time. Which of these components (upland terrestrial or downstream aquatic) is greater in a given catchment will depend upon the spatial structure of the landscape and temporal patterns in rainfall.

Over the past two years we have been monitoring rainfall amount, rainfall rate and chemistry, as well as the extent of runoff and runoff chemistry contributed from upland slopes and intermittent channels that hydrologically link the terrestrial components of the watershed with more permanent wetlands downstream. The amount of rainfall associated with individual storms, as well as the intensity of the storm, both influence the extent of flow, or hydrologic connectivity in the landscape. Small storms wet upland slopes, which occupy the terrestrial end of the continuum, but do not transport water and nutrients into channel networks. Thus, small storms may activate "hot spots" for nitrogen retention in the terrestrial component of the watershed (e.g. soils); however, as storm size and intensity increases, materials are transported from upland slopes into first and second order rivulets. During 


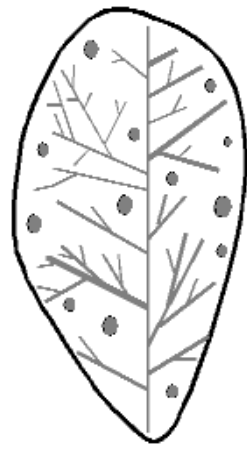

A

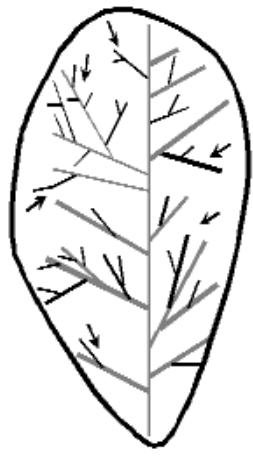

B

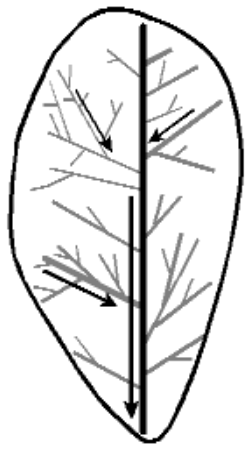

$\mathrm{C}$
FIG. 3. - Hypothetical nitrogen retention "hot spot" maps. A.) Small storms wet and activate (turn on) upland "hot spots." Rates of nitrogen retention vary across the upland landscape in relation to soil properties and moisture conditions. B.) As storm size increases, materials are mobilized and water and nutrients are transported into the intermittent channel network. During intermediate-sized storms, nitrogen retention may primarily occur in low order channels. C.) During large storms, materials are transported to the largest order channel in the catchment, where nitrogen retention may occur; however, material may also be exported to downstream ecosystems, including larger streams and lakes.

these intermediate-sized storms, low order channels may serve as collection points for materials including nitrogen and organic matter, and under high moisture conditions, these channels may experience pulses of denitrification. As storm size and intensity continues to increase, material transport extends into larger and larger channels.

\section{Retention "Hot Spots"}

Based on these data, we can produce a hypothetical "hot spot" map, depicting the spatial distribution of nitrogen transformation rates in the watershed in relation to storm size and intensity (Fig. 3). Localized zones of nitrogen retention migrate or shift further downslope with increasing storm size. Small storms wet or activate upland slopes, but as storm size increases, materials move into intermittent channels, which may shift activity to progressively larger channels. Only during the largest, relatively infrequent storms does flow reach large perennial streams, including the main stem of Sycamore Creek. Therefore, most of the time, nitrogen retention "hot spots" may be confined to the "more terrestrial" components of the watershed. Just as we see spatial gradients in moisture, vegetation density, and particle size from the terrestrial to the aquatic components of the watershed, we may see gradients in nitrogen retention that correspond with increasing storm size.
So, the question remains - where is the missing nitrogen? We suggest that nitrogen retention "hot spots" in the Sycamore Creek Watershed are variable in space and shift in relation to storm size, intensity and frequency. In order to better understand nitrogen transport and retention in watershed ecosystems, we must explicitly consider the link between the spatial structure of the watershed, from "more terrestrial" to "more aquatic" along the hydrologic flowpath, and changes in these patterns over time.

Our motivating question "where and when do important nitrogen transformations occur?" is by definition a landscape rather than an ecosystem question because it involves space in an explicit way as an independent variable. The entity of interest is the landscape and because running water perfuses the entire space, the concepts of aquatic (ecosystem) or terrestrial (ecosystem) lose meaning. Clearly this is a continuum. Traditional aquatic organisms such as fish and aquatic plants and mosquito larvae have a restricted distribution as do upland cacti and lichens and rattlesnakes. But, as we have shown, trees are crucial to the functioning of large streams and "aquatic" bacteria fix nitrogen on sporadically moist ridge tops. Viewed from the perspective of flow paths (space) and episodic climatic events (time), the desert landscape emerges as an integrated, interconnected but spatially heterogeneous whole. The challenge of understanding requires that we move beyond our compartmentalized view of ecosystems and incorporate the broader integrative view provided by landscape ecology.

\section{CONCLUSIONS}

These case studies indicate that stream ecology is expanding conceptually by becoming more spatially explicit. Resolution of ecological function in terms of flow paths, patch shapes, and material processing and/or retention has been a lucrative theme and it conceptually transforms landscapes from static mosaics to spatially explicit, dynamic, spatially-oriented continua with a strong episodic climate and weather-driven functioning. This view has tended to integrate terrestrial and aquatic ecosystems in a functionally meaningful way. Conceptual challenges persist in incorporation of lakes, estuaries, and oceans in this integrated landscape view. Surely many vectors of linkage occur in addition to the hydrologic linkages invoked in the stream landscape 
arena. Many of these involve water movements but these may be generated by wind action (currents), pressure systems (seiches), lunar cycles (tides), or rainfall. Other forces such as gravity (landslides, leaf fall, sedimentation), weather systems (atmospheric linkages), and biological factors (migration) can link subsystems in a heterogeneous landscape. We contend that these properties provide a window on cause and effect relationships (process, pattern) by separating them in space.

In many ways separation of processes in space helps to resolve them more clearly and to deduce causation more definitively than if processes occur simultaneously or are separated in time only.

\section{ACKNOWLEDGEMENTS}

This research was supported by NSF grants DEB 9727311 and DEB 0075650.

\section{REFERENCES}

Allan, J.D. - 1995. Stream ecology: structure and function of running waters. Chapman and Hall.

Busch, D.E. and S.G. Fisher. - 1981. Metabolism of a desert stream. Freshwater Biol. 11(4): 301-308.

Coleman, R.L. and C.N. Dahm. - 1990. Stream geomorphology: effects on periphyton standing crop and primary production. $J$. N. Am. Benthol. Soc., 9(4): 293-302.

Dent, C.L., N.B. Grimm and S.G. Fisher. - 2001. Multiscale effects of surface-subsurface exchange on stream water nutrient concentrations. J. N. Am. Benthol. Soc., 20: 162-181.

Fetter, C.W. - 1994. Applied hydrogeology, 3rd Edition. Macmillan College Publishing company, New York.

Fisher, S.G. - 1994. Pattern, process and scale in freshwater ecosystems: Some unifying thoughts. In: P.S. Giller, A.G. Hildrew and D.G. Rafaelli (eds), Aquatic Ecology: Scale, Pattern and Process, pp. 575-591. Blackwell Scientific Publications. Oxford.

Fisher, S.G. - 1997. Creativity, idea generation, and the functional morphology of streams. J. N. Am. Benthol. Soc., 16: 305-318.

Fisher, S.G. and G.E. Likens. - 1973. Energy flow in Bear Brook, New Hamsphire: an integrative approach to stream ecosystem metabolism. Ecol. Monogr., 43: 421-439.

Fisher, S.G., L.J. Gray, N.B. Grimm and D.E. Busch. - 1982. Temporal succession in a desert stream following flash flooding. Ecol. Monogr., 52(1): 93-110.

Fisher, S.G. and L.J. Gray. - 1983. Secondary production and organic matter processing by collector macroinvertebrates in a desert stream. Ecology, 64: 1217-1224.

Grimm, N.B. - 1987. Nitrogen dynamics during succession in a desert stream. Ecology, 68: 1157-1170.

Grimm, N.B. and S.G. Fisher. - 1986. Nitrogen limitation in a Sonoran Desert Stream. J. N. Am. Benthol. Soc., 5: 2-15.

Grimm, N.B. and S.G. Fisher. - 1992. Responses of arid land streams to changing climate. In: P. Firth and S.G. Fisher (eds.), Global Climate Change and Freshwater Ecosystems, pp. 211233. Springer-Verlag, New York.

Groffman, P.M., A.J. Gold and R.C. Simmons. - 1992. Nitrate dynamics in riparian forests: Microbial studies. J. Environ. Oual., 21: 666-671.

Gutshick, V.P. 1981. Evolved strategies in nitrogen acquisition by plants. Am. Nat., 118(5): 607-637.

Harvey, J.W. and B.J. Wagner. - 2000. Quantifying hydrologic interactions between streams and their subsurface hyporheic zones. In: J.B. Jones, Jr., and P.J. Mulholland, (eds.), Streams and Groundwaters, pp. 3-44. Academic Press.

Hill, A.R. - 2000. Stream chemistry and riparian zones. In: J.B. Jones, Jr., and P.J. Mulholland (eds.), Streams and Ground Waters, Academic Press.

Holmes, R.M., S.G. Fisher, and N.B. Grimm. - 1994. Parafluvial nitrogen dynamics in a desert stream ecosystem. J. N. Am. Benthol. Soc., 13: 468-478.

Holmes, R.M., S.G. Fisher and N.B. Grimm. - 1995. Denitrification in a nitrogen-limited stream ecosystem. Biogeochemistry. 33: 125-146.

Horton, R.E. - 1945. Erosional development of streams and their drainage basins: hydrophysical approach to quantitative morphology. Geol. Soc. Am. Bull., 56: 281-300.

Likens, G.E., F.H. Bormann, N.M. Johnson, and R.S. Pierce. 1967. Tha calcium, magnesium, potassium, and sodium budgets for a small forested ecosystem. Ecology, 48; 772-785.

Lowrance, R.R. - 1998. Riparian forest ecosystems as filters for nonpoint-source pollution. In: M.L. Pace and P.M. Groffman, (eds.), Successes, limitations and frontiers in ecosystem science, pp. 113-141. Springer-Verlag.

Lowrance, R.R., R. Todd, J. Fail, O. Hendrickson, R. Leonard, and L. Asmussen. - 1984. Riparian forests as nutrient filters in agricultural watersheds. Bioscience, 34: 374-377.

Marti, E., S.G. Fisher, J.J. Schade and N.B. Grimm. - 2000. Flood frequency, arid land streams. and their riparian zones. In: J.B. Jones and P.J. Mulholland (eds.), Streams and Ground Waters, pp 111-136. Academic Press. San Diego.

McClain, M.E., J.E. Richey, and T.P. Pimetel. - 1994. Groundwater nitrogen dynamics at the terrestrial-lotic interface of a small catchment in the Central Amazon Basin. Biogeochemistry, 27: 113-127.

Meentemeyer, V. and E. Box. - 1987. Sale effects in landscape studies. Landscape heterogeneity and Disturbance M.G. Turner (ed.) Pp 15-34. Springer Verlag. N.Y.

Meyer, J.L. and G.E. Likens. - 1979. Transport and transformation of phosphorus in a forest stream ecosystem. Ecology, 60: 1255-1269.

Newbold, J.D., J.W. Elwood, R.V. O'Neil and W. Van Winkle. 1981. Measuring nutrient spiralling in streams. Can. J. Fish. Aquat. Sci., 38: 860-863

Newbold, J.D., R.V. O'Neill, J.W. Elwood and W. Van Winkle. 1982. Nutrient spiraling in streams: Implications for nutrient limitations and invertebrate activity. Am. Nat., 120: 628-652.

Ohte, N., N. Tokuchi and M. Suzuki. - 1997. An in situ lysimeter experiment on soil moisture influence in inorganic nitrogen discharge from forest soil. J. Hydrology, 195: 78-98.

O'Neill, R.V., D.L. DeAngelis, J.B. Waide and T.F.H. Allen. 1986. A hierarchical concept of Ecosystems. Princeton University Press, Princeton.

Peterjohn, W.J. and D.L. Correll. - 1984. Nutrient dynamics in an agricultural watershed: observations on the role of the riparian forest. Ecology, 65: 1466-1475.

Peterjohn, W.T. and W.H. Schlesinger. - 1990. Nitrogen loss from deserts in the southwestern United States. Biogeochemistry 10: 67-79.

Pickett, S.T.A., J. Kolasa, J.J. Armesto and S.L. Collins. - 1989. The ecological concept of disturbance and its expression at various hierarchical levels. Oikos, 54: 129-136.

Schade, J.D. and S.G. Fisher. - 1997. The influence of leaf litter on a Sonoran desert stream ecosystem. J. N. Am. Benthol. Soc., 16(3): 612-626.

Schade J.D., E. Marti, J.R. Welter, S.G. Fisher and N.B. Grimm. 2001a. Sources of $N$ to the riparian zone of a desert stream: implications for riparian vegetation and nitrogen retention. Ecosystems, (in press).

Schade, J.D., S.G. Fisher, N.B. Grimm and J.A. Seddon. - 2001b. The influence of a riparian shrub on nitrogen cycling in a Sonoran Desert Stream. Ecology, (in press).

Schlesinger, W.H., A.D. Abrahams, A.J. Parsons, and J. Wainwright. - 1999. Nutrient losses in runoff from grassland and shrubland habitats in Southern New Mexico: I. rainfall simulation experiments. Biogeochemistry 45(1): 21-34.

Sellers, W.D. and R.H. Hill. - 1974. Arizona Climate. Univ. of Arizona Press. Tucson. 616 pp.

Sinsabaugh, R.L., T. Weiland and A.E. Linkins. - 1991. Epilithon patch structure in a boreal river. J. N. Am. Benthol. Soc., 10: 419-429. 
Sprent, J.I. - 1987. The ecology of the nitrogen cycle. Cambridge University Press, Cambridge.

Strahler, A.N. - 1964. Quantitative geomorphology of drainage basins and channel networks. In: V.T. Chow (ed.), Handbook of Applied Hydrology. McGraw-Hill, New York.

Stanley, E.H., S.G. Fisher and N.B. Grimm. - 1997. Ecosystem expansion and contraction: a desert stream perspective. BioScience, 47: 427-435.

Triska, F.J., V.C. Kennedy, R.J. Avanzino, G.W. Zellweger and K.E. Bencala. - 1989. Retention and transport of nutrients in a third-order stream in northwestern California: Hyporheic processes. Ecology, 70: 1893-1905.

Turner, M.G. - 1989. Landscape Ecology: the Effects of pattern on Process. Ann. Rev. Ecol. Syst., 20: 171-197.

Valett H.M., S.G. Fisher and E.H. Stanley. - 1990. Physical and chemical characteristics of the hyporheic zone of a Sonoran Desert stream. J. N. Am. Benthol. Soc., 9: 201-215.

Vitousek, P.M. and W.A. Reiners. - 1975. Ecosystem succession and nutrient retention: a hypothesis. BioScience, 25: 376-381. 